\title{
Gender Sensitivity, Mental Health Care Provision and Minority Communities in Ireland: A Realist Analysis
}

\author{
Bergin $\mathbf{M}^{* 1}$, Wells JSG ${ }^{2}$ and Owen $\mathrm{S}^{3}$ \\ 1Department of Nursing \& Health Care School of Health Sciences, Waterford Institute \\ of Technology, Ireland \\ ${ }^{2}$ School of Health Sciences, Waterford Institute of Technology, Ireland \\ ${ }^{3}$ College of Social Science, University of Lincoln, Brayford Pool, UK
}

\section{Research Article \\ Volume 1 Issue 1}

Received Date: August 08, 2017

Published Date: August 23, 2017

DOI: $10.23880 / \mathrm{mhrij}-16000106$

*Corresponding author: Michael Bergin, Department of Nursing \& Health Care School of Health Sciences, Waterford Institute of Technology, Ireland, Tel: 0035351845549; E-mail: mbergin@wit.ie

\section{Abstract}

The Irish Government has adopted "Gender Mainstreaming" as a strategy to promote equal opportunities between women and men in its National Development Plan. While current mental health policy addresses the principle of partnership and social inclusiveness as a way forward for mental health service provision, it still does not explicitly deal with the notion of gender and gender sensitivity. For some minority groups a lack of trust is a key issue that affects their uptake and meaningful use of services resulting in inadequate and gender insensitive care provision.

Aim: The aim of this paper is to describe and analyse service providers' views in relation to the gender sensitivity of mental health care provision particularly as it relates to minority (Traveller and gay) communities.

Method: A qualitative social realist design was used guided by Layder's adaptive theory and ontological theory of the social world - 'social domains theory'. In-depth interviews with twenty eight service providers were conducted within one mental health service in Ireland. Data was analysed using NVivo software.

Results: The findings are presented in relation to tolerance and responsiveness of service providers towards the gay and Traveller communities. Service providers suggested that prejudices were held in relation to both indigenous and immigrant minority groups and this impacted upon care provision. Categorical intersectional understandings of gender were used by service providers to describe Travellers.

Conclusion: Belonging to a minority group was a potential or actual threat to gender sensitive care and service providers managed such threats within a lay socialisation context. Arguably, a move towards developing gender-sensitive mental health care provision requires greater collaboration, education and understandings in relation to minority groups, their cultural differences and gendered identities.

Keywords: Gender Sensitivity; Mental Health; Communities; Gender; Performative; Intersectionality 


\section{Mental Health \& Human Resilience International Journal}

\section{Introduction}

Irish mental health policy and care provision is criticised for being gender-neutral and gender insensitive [1], despite gender being a critical determinant of mental health and illness [2]. There is now a growing recognition for the inclusion of both "sex" and "gender" sensitivity within health service delivery and research [3]. Indeed, gender is considered significant in the transformation of the physical body (sex) to the social (gender) and it is this gendered identity that allows for a gender analysis of illnesses and care provision [4]. There is mixed evidence that supports both biological (sex) and sociological (gender) risk factors for some mental illnesses [5] with the significance of social issues in relation to the causation of depression highlighted [6].

The Irish Government have adopted "Gender Mainstreaming" as a strategy to promote equal opportunities between women and men $[7,8]$ and to make women's and men's concerns and experiences a central dimension in the design, implementation, monitoring and evaluation of policies and programmes in all political, economic and social spheres [9]. For example, the recent Thirty-fourth Amendment to the Constitution of Ireland gives permission for marriage to be contracted by two persons without distinction as to their sex [10] and this was the first time that a state legalised same-sex marriage through a popular vote.

Understandings of gender as 'categorical', 'relational' and 'performative' are current within the literature. For instance, socio-biological approaches to gender include what Connell [11] refers to as 'categoricalism', an essentialist view whereby masculinity and femininity are seen as natural opposites, expressing difference of male and female bodies [12]. Categorical thinking can be based either on biological differences or on the sex role model of gender whereby a dichotomy exists in terms of social norms and expectations rather than anatomy [12]. Categorical thinking understands men and women as two homogenous groups based upon a bio-social perspective, and this approach for a gendered analysis of health issues is regarded as only a good starting point [13]. This categorical approach is sometimes cross-referenced with other categories, for example race, class, sexuality, culture or age - a process referred to as 'intersectionality' [14].

Gender-relational theory understands gender as multidimensional [15] and explores economic, power, affective and symbolic relations that operate at intrapersonal, interpersonal, institutional and societal levels [4,12]. 'Relationality' refers to the interconnectedness and social relations that exist within phenomena and how gendered identities are constructed based on social practices [15]. Therefore, this approach addresses how gender structures change over time and how performing masculinity and femininity bring a social reality, for example, how issues relating to gender, health and illness are created, sustained or changed for various individuals or groups of people [16].

Poststructuralist gender theorists suggest that gender is something that is not expressive but evolves from people 'doing gender' through their everyday communications - 'performative' [17-19]. Butler [17] similar to de Beauvoir [20] rejects any belief that gender differences are biological in origin and argues that gender is created and brought into being by the actions of how people conduct themselves as gendered beings, leading to understandings that are masculine or feminine. Poststructuralist theory has successfully challenged gender essentialism with a particular focus on culture and the cultural dimensions of various groups (both mainstream and minority communities).

Irish Travellers are an indigenous minority group and have a distinctive lifestyle and culture, based on a nomadic tradition that sets them apart from the general Irish population. Their value system, language, customs and traditions make them an identifiable group both to themselves and to others and it is estimated that somewhere in the region of 40,000 Travellers live on the island of Ireland [21]. Shelta is a language spoken by Irish Travellers [22,23] and they use a secret argot (jargon) known as Gammon to primarily exclude or conceal meaning from outsiders with many gammon utterances being abrupt and spoken so quickly that non-Travellers might conclude that the language used was merely garble [24]. The All Ireland Traveller Health Study (AITHS) found that the doctor/patient experience was particularly fraught for Travellers and that while mental health services were available they were often perceived as inadequate with a lack of trust emerging as a key issue for Travellers in their uptake and meaningful use of services [21]. This paper therefore describes and analyses service providers' views in relation to the gender sensitivity of care provision for men and women particularly as it relates to minority communities - Traveller and gay communities. A gender sensitive approach to health care is considered as 'an understanding of the socio-political 


\section{Mental Health \& Human Resilience International Journal}

context in which the need for, and nature of, health care takes place' [25].

\section{Methodology and Approach}

A qualitative social realist design was used guided by Layder's [26] adaptive theory and his ontological theory of the social world - 'social domains theory'. Layder [27] argues that the social world is made up of four social domains that relate to the subjective and objective dimensions of society. They are (1) 'psychobiography' (individual); (2) 'situated activity' (inter-subjective and relational; (3) 'social settings' (social contexts or locations in which situated activity occurs) and (4) 'contextual resources' (discourses and language, cultural values, beliefs, norms, inequality of class, gender and power differences). These four social domains allow for understandings of gender at individual, relational, institutional and resource levels.

The sample $(n=28)$ consisted of a cross section of service providers (psychiatric nurses, psychiatrists, psychologists, occupational therapists and social workers) from one mental health service in Ireland. Theoretical sampling from an adaptive theory approach was used to select and develop the sample [26]. A feminist interviewing approach was used as the study required an interview process that was balanced between structure and flexibility so that an in-depth exploration of gender issues (potential sensitive areas) could be achieved [28]. This allowed the researcher to move freely beyond the formal role of the neutral asker and express and share information, resembling normal conversation where the interviewee influences the exchanges [29].

Individual interviews took place in a variety of settings, including day hospitals, day centres and acute clinical areas. The duration of interview varied between 30 and 70 minutes and permission to tape-record interviews was given by all participants. A topic guide was used as a mechanism for steering discussion but was not prescriptive in nature [30] and reflected a gender awareness framework exploring three key areas related to ideology, sensitivity and knowledge. Interview data were entered into a qualitative data analysis computer package - NVivo and analysed using an adaptive theory approach [26]. Ethical approval was granted by the Regional Ethics Committee, Health Service Executive (HSE) South East Area, Ireland.

\section{Findings}

The findings are presented in relation to tolerance and responsiveness of service providers towards the gay and Traveller communities. The following abbreviations are used: SPm - service provider male and SPf - service provider female.

\section{Tolerant and Responsive to Minority Communities}

Minority groups, particularly the Traveller and gay communities were highlighted and stereotyped (mostly negative) by service providers. Service providers used the process of 'intersectionality' whereby categories of gender (men and/or women) were cross-classified with another category (sexuality, culture) to describe the gendered identities of individuals. This led to an individuals' gendered identity being defined in terms of the collective stereotype of the cross-classified category.

There was a commitment by service providers to be open and receptive to minority groups and to avoid any discriminatory or prejudicial related ideologies or behaviours. However, there was evidence of divergent thinking amongst service providers. Some viewed minority groups as no different from mainstream service users. Culture, race, gender and sexuality were not negatively influential factors for care provision. One female nurse stated: 'we see their needs, treat and care accordingly' (SPf24). Others meanwhile suggested that while they aspired to views that were non-prejudicial they 'probably did not achieve this in reality' (SPm18). Indeed, nursing staff that previously worked in other jurisdictions outside of Ireland described African and Asian communities as sometimes 'threatening and in your face' (SPm13). This resulted in ideology and care provision that was gender insensitive.

Service providers described Ireland as a traditionally homogenous conservative country, and as a consequence, suggested prejudices were held in relation to both indigenous and immigrant minority groups, that impacted upon care provision. Therefore, 'bridging the gap' between mainstream society and minority groups was considered important in developing care provision that was gendered. However, service providers often felt 'powerless as they did not fully understand minority cultures, [their] values and beliefs and how [such 


\section{Mental Health \& Human Resilience International Journal}

attributes] influenced gender identity' (SPm6). Service structures and resources were regarded by service providers as insufficiently developed to meet the gendered needs of these groups.

\section{Gay People and Care Provision}

Overall, service providers were open to alternative life styles and being gay was not an issue for them. As suggested by a female nurse:

'Gay people are well respected... never been an issue... you don't jeer anyone. I don't think they felt any different in the way they were treated. Not an issue and we should not make it one' (SPf19).

Gay people were seen by some as a 'homogenous group' and stereotyped as 'marginalised', 'effeminate' and 'vulnerable'. There was a view by most service providers that all gay men were 'more emotionally open and expressive' inconsistent with attributes of hegemonic/complicit masculinities.

A number of nurses suggested that services were not gender sensitive for gay people and this may have been attributed to service providers assuming dominant societal norms and values for men that were based upon hegemonic/complicit masculinities. Many suggested that gay service users often conceal their sexual identity so as 'to fit in' at service level. There was a belief that gay service users find it difficult to be 'out' or 'gay' at ward level and required additional protection from the potential threat of being gay. Consequently, they needed to be observed more closely. Concerns were expressed that if they were 'out to the ward they might be jeered or mocked 'and get a 'hard time' from other service users. A female allied health professional typifies how being gay was stereotyped and associated with subordinate masculinity and femininity only.

'I think there is a difference... between men and women and how services need to respond to them... women can tap and express feelings more easily whereas men I need to be more cautious and go slower and a lot more trust needed to establish the relationship and for them to feel more safe and secure. In reference to the gay culture I think there is a difference to a gay male and a non-gay male in terms of openness of sharing feelings... the gender is the same... male /male but from a sub culture I think the gay guys are far more open to sharing and showing their feelings' (SPf11).
A female nurse illustrated a potential threatening situation and anticipated negative outcomes for a gay male cross dresser. Her use of language highlighted that gay people were viewed differently to mainstream service users. There was both sexual and gendered stereotyping with anticipatory risk management leading to restrictive service provision.

'We had a man admitted who was a homosexual and he wanted to dress up as a woman and was taking medication for that and he wanted to be admitted to the female ward but we could not do because he was technically a man... so the only option was to place him in the pre discharge which is a mixed ward and he had a single room... so what do you do with them. So what do you do with them...he would have been killed up there [segregated ward].He had the insight to know he could not go up there but it is awful that he had to pretend to be someone else to fit in... the showers and the bath areas would have been a disaster' (SPf1).

There was a view by many service providers that 'their problems' [psychological difficulties] were somehow different to mainstream service users' problems and that specific and additional resources were required to manage their issues.

'There are certain issues that they [gay people] would have but whether you would have the disciplines [professionals] or resources to deal with their problems is questionable. We would see people [minority groups] for example who are gay for support only [but]I am not a counsellor... but I would allow them to ventilate[how they are feeling] (SPf5).

Language used by service providers highlighted that gay people were viewed with 'difference' compared to mainstream society. For example, one female nurse stated:

'You don't see an awful lot of them here' (SPf1).

Service providers' use of language and being conscious of the choice of words used when probing a person's background and relational issues were highlighted (SPm6). It was suggested by one female allied health care provider that 'health professionals' are often not aware of a person's gendered identity and 'our questioning' of service users can sometimes be insensitive with a tendency to 'assume' and use categorical gendered terms. For example, husband/wife as opposed to partner or being married as opposed to 'in a relationship'. As stated 


\section{Mental Health \& Human Resilience International Journal}

by a female allied health professional.

II think actually we have got not to assume... you are assuming that because you are biologically male or female that you belong to a specific sexual group and I know because of my own orientation [sexual] that I have become very aware of my own questioning and how manly or womanly you look. I would ask about the partner or have you had a relationship with a male or a female' (SPf11).

Overall, therefore it could be said that service providers at a relational level were sensitized and hypervigilant towards the needs of gay people. However, it could be argued that at a contextual resource level service providers' use of language was less sensitive. The view that there was a 'difference' about gay people compared to mainstream service users was highlighted. Such differences had potential for threatening situations to occur with gay service users viewed as requiring extra protection. While service providers identified the concepts 'different' and 'homogeneity' as descriptors for gay people - categorical intersectional gendered understandings; gender as diversity was not evident.

\section{Travellers}

Categorical intersectional understandings of gender were used by service providers to describe Travellers. They were regarded as a 'unique' indigenous minority group and were treated differently. They were seen by some as a 'protective, cohesive community' (SPm6). Care provision tended to be less sensitive and this was largely attributed to a negative engagement with services. It was reported Travellers used services regularly but with no real therapeutic purpose. Mostly, they arrived to the services 'in crises' (SPf7) and these crises were often due to legal reasons or pending court cases. Once the crisis was dealt with they tended 'not to hang around'(SPf5). Both women and men were seen by some as demanding with men slower to engage services. There was a view that Traveller men were controlling and dominant of Traveller women with the women tending to have low self-esteem issues.

'Travellers... they have high numbers compared to the rest [other minority groups]. I think you might sub-consciously [see and treat them differently] but you do not mean to do it. It is their culture and they are so rude and demanding... they forget they are not at home but in a hospital. Once they [Travellers] are better they do not hang around. Travellers don't have as much stigma about coming to hospital as other groups do. It is a hospital to them, some of the youngers [younger adults] will say I am in the mental' (SPf1).

Service providers did not have a predisposition towards Traveller men compared to other men service users. Service providers' views were more based upon personal attributes (demanding, controlling) and less so upon care needs and this view was similar for all men. Whilst all women were viewed as demanding Traveller women were less compliant with care provision compared to other women.

'There is a view that Travellers may be trying to cod you and you let them know you know and consequently services may not be as sensitive' (SPf9).

'Travellers can be rude and demanding in getting their needs met and that they are not in their own homes now' (SPf14).

Most service providers suggested Travellers 'abused services' and that follow-up appointments were rarely attended. Poor compliance with follow-up care was a regular occurrence (SPf24) with inadequate levels of formal education and illiteracy problems cited as reasons for their lack of engagement.

There was consensus among service providers that more collaboration, education and information were required in relation to Traveller culture. This could possibly lead to an improved gendered understanding of their needs, thereby reducing the potential of 'offending them'(SPf17). The importance of understanding their use of language was also highlighted.

'...we should have open sessions for the different minority groups; for us to meet them and find out from them and what they need and their different ethnic needs; talk to the Traveller groups and both of us educating each other. I was involved in a programme with Travellers and they used to talk about the services and we would look into how they lived their lives, it was an invaluable experience. They are very family oriented and value the extended family and the elderly. Drink [alcohol] was a major issue... we learned a lot from them and what they needed from the service and what we needed to learn from them without offending anybody in the process' (SPf20).

At a contextual resource level, the use of language by minority groups was highlighted in relation to challenges in understanding what was being expressed by service users. This was particularly evident in relation to 


\section{Mental Health \& Human Resilience International Journal}

Travellers where English was their spoken language. One female nurse described her experiences of working with a Traveller in terms of language.

'We had one [service user from the Traveller community] in Dxхxхxх and they would be teaching you their language and the words they use to explain how they feel' (SPf15).

Furthermore, service providers suggested that health professionals need to recognise that Travellers often express symptoms that have specific meaning for them and that service providers may not recognise immediately the meaning and significance of what was being conveyed. This influenced sensitivity of care provision.

'Yeah I think our teaching in general... we do not have enough knowledge about these groups [sensitivity of services for minority groups] and their specific needs... we may not have an intimate knowledge of their special needs. That is a big problem and how that is to be addressed I don't know. I suppose some more liaisons between us and the travelling community... there is a lot of Traveller awareness courses. The mechanism in how they are referred [to the services] is the same [but] they could be expressing symptoms in their own way that we may not understand what they are describing, even the language they might use and how they might describe it. I think that is something that we have not got training in' (SPm2).

Overall, therefore it could be said that greater collaboration, education and understanding is required in relation to minority groups, their cultural differences and gendered identities. Intersectional understandings for gender were identified in relation to gay people and Travellers with the person's gendered identity defined in terms of their collective minority group status.

The use of language at relational and contextual resource levels was used to illustrate how minority groups may differ from mainstream society and how this impacts care provision at a gender sensitive level. While service providers suggested the concepts 'different' and 'homogeneity' as descriptors for minority groups of service users; understandings of gender as diversity was not evident. Arguably, a minority group status was a potential and actual threat for gender sensitive care.

\section{Discussion}

Categorical thinking describes gender either as being based upon biological differences or on the sex role model of gender whereby a dichotomy is in terms of social norms and expectations rather than anatomy [12].
Therefore, categorical approaches put forward a single approach for the allocation of men or women to their social positions and the acceptance of their social roles, whether based on biology, the organisation of sexual reproduction, or the capitalism of family life [15].

Categorical approaches have been cross referenced with other categories, for example race, class, sexuality, culture or age. This process is referred to as 'intersectionality' [14,31] and some feminist researchers argue that it is one of the most important theoretical approaches for women's studies [14], and also, in the 'decentring' of gender analyses [32]. However, it is criticised as still being categorical as it combines one category with another, for example, older white men or Traveller women [13]. Categorical thinking is criticised for underplaying diversity and not understanding and developing the dynamics of gender in relation to historical processes and the ways gender orders are created and gender inequalities are formed and challenged $[11,13]$.

Findings from this study identified intersectional understandings for gender in relation to the gay people and Travellers with the person's gendered identity defined in terms of their minority group status. The use of language at relational and contextual resource levels was used to illustrate how minority groups may differ from mainstream society and how this potentially impacts the views of service providers and care provision. While service providers suggested the concepts 'different' and 'homogeneity' as descriptors for minority groups of service users; understandings of gender as diversity was not evident, supporting Connell's [12,13] critique of this approach for understanding the complexities of gender. Belonging to a minority group was arguably a potential or actual threat to gender sensitive care based upon intersectional understandings of gender. The notion of a gendered individual within a minority group was less apparent.

The capacity for humans to acquire language is a universal attribute and is realized through humans engaging with each other and their wider social world [33]. Layder's [27] realist social theory offers sociolinguistics an understanding of how language impacts at a psychobiographical, situated activity, contextual resource and social setting levels [27]. As stated above, the use of language at relational contextual resource levels was used to illustrate how minority groups may differ from mainstream society and how this may impact care provision. This was particularly evident 


\section{Mental Health \& Human Resilience International Journal}

in relation to Travellers where English was their spoken language. It was highlighted that health professionals need to recognise that Travellers often express symptoms that have specific meaning for them and that service providers may not detect immediately the significance of what is being conveyed to them. Language used by service providers also highlighted how gay people were viewed as 'different' compared to mainstream society. This was thought to influence gender sensitivity and care provision at a contextual resource level, and arguably, belonging to a minority group was a potential or actual threat to gender sensitive care.

The literature on the medical encounter between health professionals and lay people is replete with accounts of negative doctor/patient interactions and communications [34-38]. Minority groups often receive insufficient information and are not encouraged participating in their clinical decision making [39].The All Ireland Traveller Health Study (AITHS) found that the doctor/patient experience was particularly fraught for Travellers and the use and uptake of primary services was scant [21]. The findings showed that while mental health services were available they were often perceived as inadequate. Trust emerged from the focus groups as a major issue for Travellers in their uptake and meaningful use of health services and the expanding literature on this area currently reflects the importance of the relationship between trust and health $[40,41]$.

In this study, Travellers were viewed as a 'protective community' and tended to negatively engage and 'abuse services'. As a result, service providers were less trustful of Travellers and their views less gender sensitive. Travellers used services regularly but with no real therapeutic purpose. They arrived to the services 'in crises' and poor compliance with care programmes and follow up were regular occurrences. Education and training into their culture and language was suggested as ways for developing improved trust and sensitivity of care provision.

\section{Concluding Comments}

This paper described and analysed service providers' views with regard to the responsiveness and gender sensitivity of care provision for men and women from minority groups. 'Intersectionality' and categorical understandings for gender in relation to gay people and Travellers was evident with a person's gendered identity defined in terms of their minority group status. The concepts 'different' and 'homogeneity' were descriptors used in relation to minority groups with understandings of gender as diversity not evident.

Greater collaboration, education and understanding are required in relation to minority groups, their cultural differences and gendered identities. Data was analysed with reference to Layder's [27] ontological theory of the social world - 'social domains theory'. In particular, the use of language at a situated activity (relational) and contextual resource levels was used to illustrate how minority groups may differ from mainstream society. Belonging to a minority group was a potential or actual threat to gender sensitive care and arguably service providers managed such threats within a lay socialisation context.

\section{References}

1. Bergin M, Wells JSG, Owen S (2013) Towards a gendered perspective for Irish mental health policy and service provision. Journal of Mental Health 22(4): 350-360.

2. World Health Organisation (2001) The World Health Report 2001 Mental Health: New Understanding, New Hope. World Health Organisation, Geneva.

3. World Health Organisation (2004) Gender in Mental Health Research. World Health Organisation, Geneva.

4. Lorber J, Moore LJ (2002) Gender and the Social Construction of Illness. Aalta Mira Press, Oxford.

5. Payne S (2006) The Health of Men and Women. Polity Press, Cambridge.

6. Brown GW, Harris TO (1978) Social Origins of Depression. Tavistock, London.

7. United Nations (1997) Mainstreaming the Gender Perspective into all Policies and Programmes in the United Nations. United Nations, New York.

8. World Health Organisation (2007) Glosssary, at www.euro.who.int/GEM/strategy/20070426-7, accessed 19 February 2011

9. NDP Gender Equality Unit (2003) Assessment of the Main Gaps in Existing Information on Women in Agriculture. NDP Gender Equality Unit, Department of Justice, Equality and Law Reform, Dublin. 


\section{Mental Health \& Human Resilience International Journal}

10. Government of Ireland (2015) Marriage Act 2015, Office of the Attorney General, Dublin

11. Connell R (1987) Gender and Power. Polity, Press in association with Blackwell Publishing Ltd, Cambridge.

12. Connell R (2009) Gender in World Perspective, short introductions, 2nd edition. Polity Press, Cambridge.

13. Connell R (2012) Gender, health and theory: conceptualizing the issue, in local and world perspective. Social Science \& Medicine 74(11): 16751683.

14. McCall L (2005) The complexity of intersectionality. Signs 30(3): 1771-1800.

15. Howson R (2006) Challenging Hegemonic Masculinity. Routledge Taylor \& Francis Group, London

16. Connell R (2005) Masculinities, 2nd edition. Polity Press in association with Blackwell Publishing Ltd, Cambridge.

17. Butler J (1990) Gender Trouble: Feminism and the Subversion of Identity. Routledge, London.

18. Butler J (2004) Undoing Gender. Routledge, Oxfordshire.

19. West C, Zimmerman DH (1987) "Doing gender", Gender and Society 1(2): 125-151.

20. Beauvoir S de (1982) The Second Sex. Penguin, Harmondsworth.

21. Department of Health \& Children, Department of Health, Social Services \& Public Safety (2010) All Ireland Traveler Health Study, All Ireland Traveler Health Study. Team School of Public Health, Physiotherapy and Population Science, University College Dublin, Dublin.

22. Kirk J, Ó Baoill D (2002) Travellers and their Language. Queen's University, Belfast.

23. McArthur $T$ (1992) The Oxford Companion to the English Language. Oxford University Press, Oxford, 22(3): 449-451.

24. Gmelch S (1986) Nan: The Life of an Irish Travelling Woman. Souvenir Press, London.
25. Miers M (2002) Developing an understanding of gender sensitive care: exploring concepts and knowledge. Journal of Advanced Nursing 40(1): 6977.

26. Layder D (1998) Sociological Practice, Linking Theory and Social Research. Sage Publications, London.

27. Layder D (1997) Modern Social Theory, Key Debates and New Directions. Routledge, London.

28. Olsen W (2004) Methodological triangulation and realist research, an Indian exemplar. In: Carter B \& New C (eds), Making Realism Work, Realist Social Theory and Empirical Research, Critical Realism Interventions. Routledge Taylor \& Francis Group, London, pp: 135-150.

29. Rubin HJ, Rubin IS (2005) Qualitative Interviewing, The Art of Hearing Data, 2nd edition. Sage Publications Inc., Thousand Oaks, California.

30. Arthur S, Nazroo J (2003) Designing fieldwork strategies and materials. In:Ritchie J \& Lewis J (eds), Qualitative Research Practice, A Guide for Social Science Students and Researchers. Sage Pubications, London, Pp: 109-137.

31. Crenshaw K (1991) Demarginalizing the intersection of race and sex: a black feminist critique of antidiscrimination doctrine, feminist theory, and antiracist politics. In: Bartlett KT \& Kennedy R (eds), Feminist Legal Theory. Boulder, Westview, pp: 57-80.

32. Hankivsky O (2012) Women's health, men's health, and gender and health: implications of intersectionality. Social Science \& Medicine 74(11): $1712-1720$.

33. Carter B, Sealey A (2004) Researching 'real' language. In: Carter B \& New C (eds), Making Realism Work, Realist Social Theory and Empirical Research, Critical Realism Interventions. Routledge Taylor \& Francis Group, London, pp: 111-130.

34. Kleinman A (1981) Patients and Healers in the Context of Culture: An Exploration of the Borderland between Anthropology, Medicine and Psychiatry. University of California Press, Berkeley, CA 25(4): 435-436. 


\section{Mental Health \& Human Resilience International Journal}

35. Helman C (1978) 'Feed a cold, starve a fever': folk models of infection in an English urban community, and their relation to medical treatment. Culture Medicine and Psychiatry 2(2): 107-137.

36. Department of Health (1992) Putting the Patient First: A Charter of Rights for Hospital Patients. The Stationery Office, Dublin.

37. Salmon P (2000) Patients who present physical symptoms in the absence of pathology: a challenge to existing models of doctor-patient interaction. Patient Education and Counselling 39: 105-113.

38. Wood B (2000) Patient Power? The Politics of Patients' Associations in Britain and America. Health Expect 4(4): 266-267.
39. Ferguson W, Candib L (2002) Culture, language, and the doctor-patient relationship. Family Medicine and Community Health (FMCH) Publications and Presentations, University of Massachusetts Medical School.

40. Alaszewski A (2003) Risk, trust and health. Health, Risk \& Society 5(3): 235-239.

41. Mechanic D (1996) Changing medical organisation and the erosion of trust. The Milbank Quarterly 74(2): 171-189. 